\title{
Propofol protects oxidative-stress-induced Cos-7 cell death by induction of autophagy
}

\author{
Seung-Wan Baik ${ }^{2}$, Eun-Jung Kim ${ }^{1}$, Ji-Young Yoon ${ }^{1}$, Cheul-Hong Kim ${ }^{1}$, Sang-Hoon Shin ${ }^{2}$, Yong-Deok Kim ${ }^{3}$ \\ ${ }^{1}$ Pusan National University Dental Hospital, Dept of Anesthesiology, Yangsan, Korea, Republic of, \\ ${ }^{2}$ Pusan National University Yangsan Hospital, Dept of Anesthesiology \& Pain Medicine, Yangsan, Korea, Republic of, \\ ${ }^{3}$ Pusan National University Dental Hospital, Dept of Surgery, Yangsan, Korea, Republic of
}

\section{Background}

In oxidative stress, reactive oxygen species (ROS) production contribute cellular dysfunction and cell apoptosis. And autophagy is though the mechanism for decreasing ROS concentration and oxidative damage. Propofol presents antioxidant properties. So in this study, we investigated whether the propofol preconditioning protects cell damage from hydrogen peroxide-induced oxidative stress and influences on cellular autophagy

\section{Materials and Method}

The groups were randomly divided into the following groups: Control; cells were incubated in normoxia $\left(5 \% \mathrm{CO}_{2}, 21 \% \mathrm{O}_{2}\right.$ and $\left.74 \% \mathrm{~N}_{2}\right)$ without propofol, hydrogen peroxide $\left(\mathrm{H}_{2} \mathrm{O}_{2}\right)$; cells were exposed to $24 \mathrm{~h} \mathrm{H}_{2} \mathrm{O}_{2}(400 \mu \mathrm{M})$, propofol preconditioning $(\mathrm{PPC})+\mathrm{H}_{2} \mathrm{O}_{2}$; cells pretreated with propofol were exposed to $\mathrm{H}_{2} \mathrm{O}_{2}$, 3-Methyladenine (3-MA)+PPC $+\mathrm{H}_{2} \mathrm{O}_{2}$; cells pretreated with 3-MA (1mM) 1 h and propofol were exposed to $\mathrm{H}_{2} \mathrm{O}_{2}$. Cell viability was determined with MTT reduction. Apoptosis was determined by Hoechst 33342 staining.

Relation with autophagy was detected with western blot analysis.

\section{Results}

Cell viability decreased significantly in $\mathrm{H}_{2} \mathrm{O}_{2}$ group and which was improved by propofol preconditioning. Propofol effectively decreased $\mathrm{H}_{2} \mathrm{O}_{2}$-induced COS-7 cell apoptosis. However, 3-MA inhibited the protective effect of propofol at cell apoptosis. In western blot analysis, autophagy related proteins were increased in $\mathrm{PPC}+\mathrm{H}_{2} \mathrm{O}_{2}$ group compared.

(A)

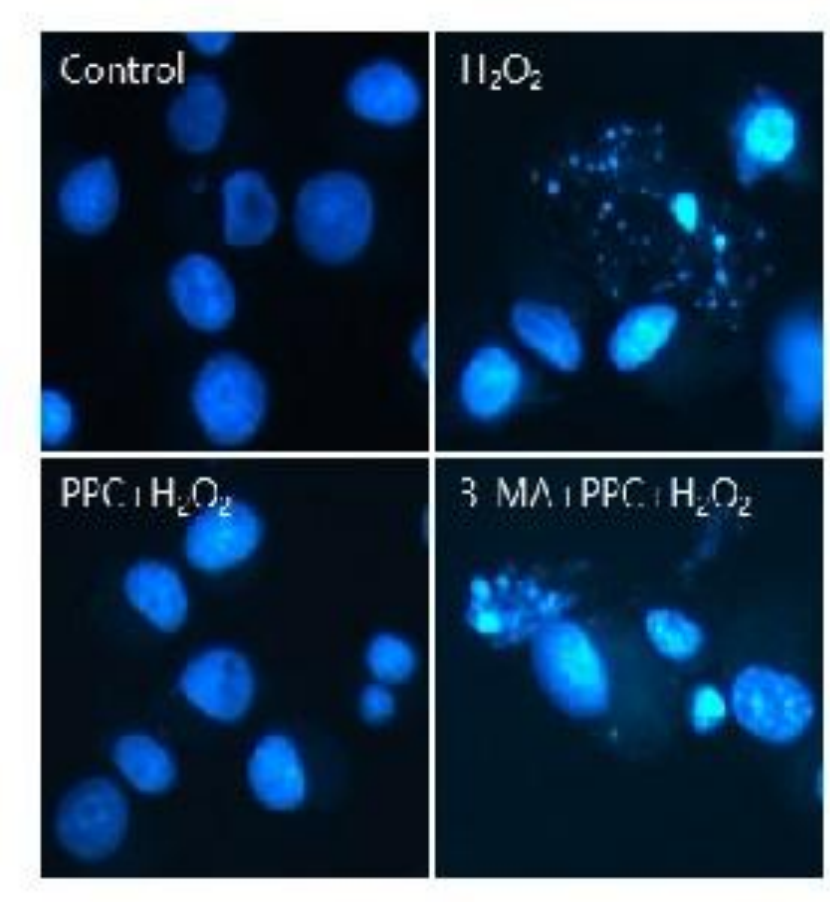

(B)
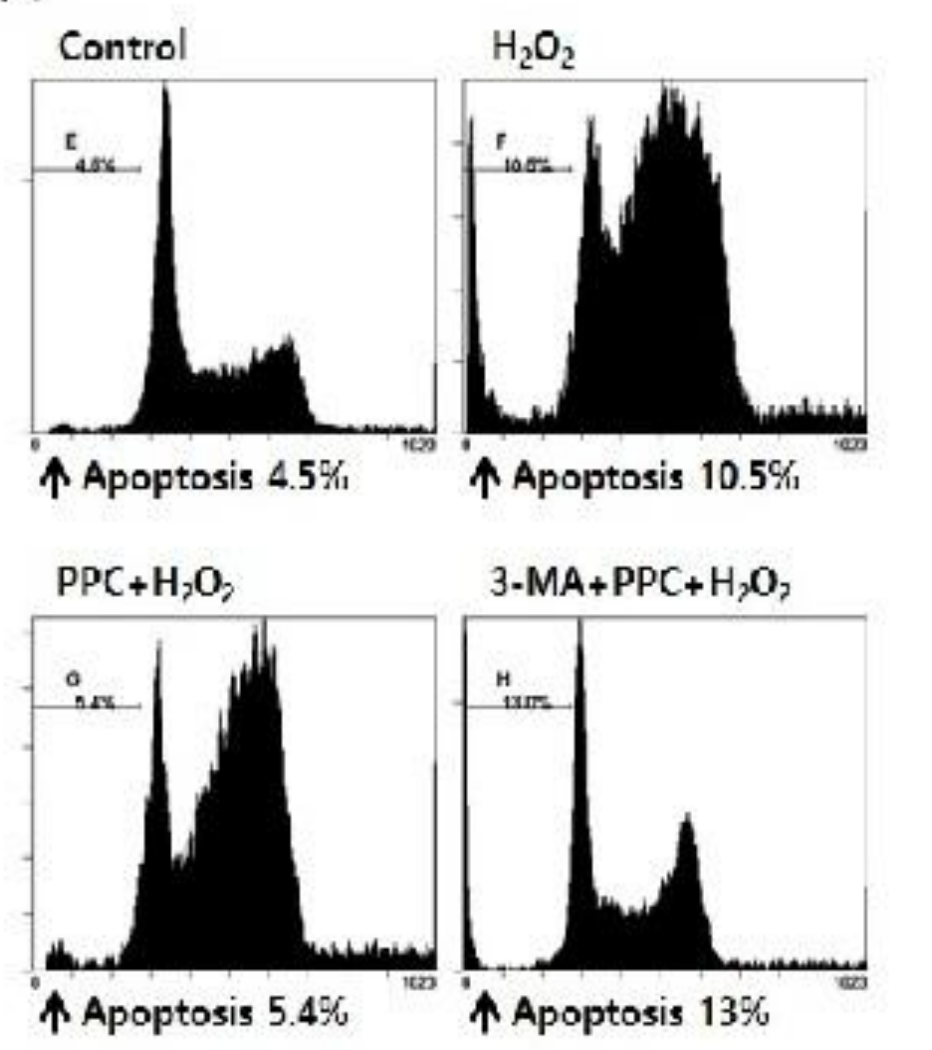
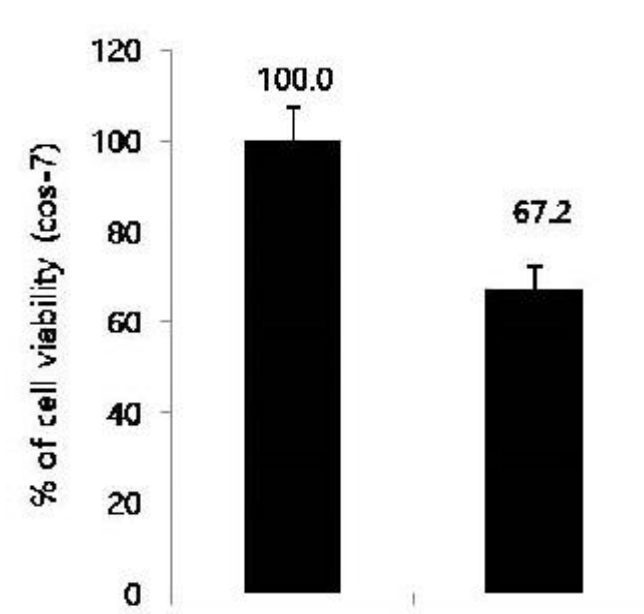

control

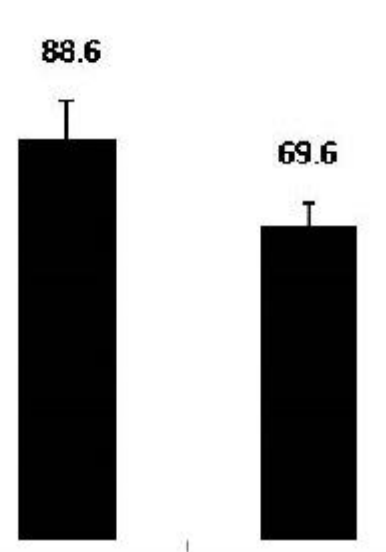

$\mathrm{PPC}+\mathrm{H}_{2} \mathrm{O}_{2} \quad 3-\mathrm{MA}+\mathrm{PPC}+\mathrm{H}_{2} \mathrm{O}_{2}$

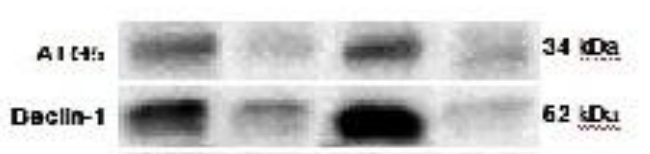

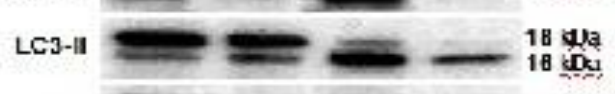

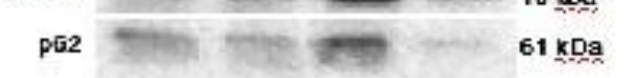

coron! - 3 kиa
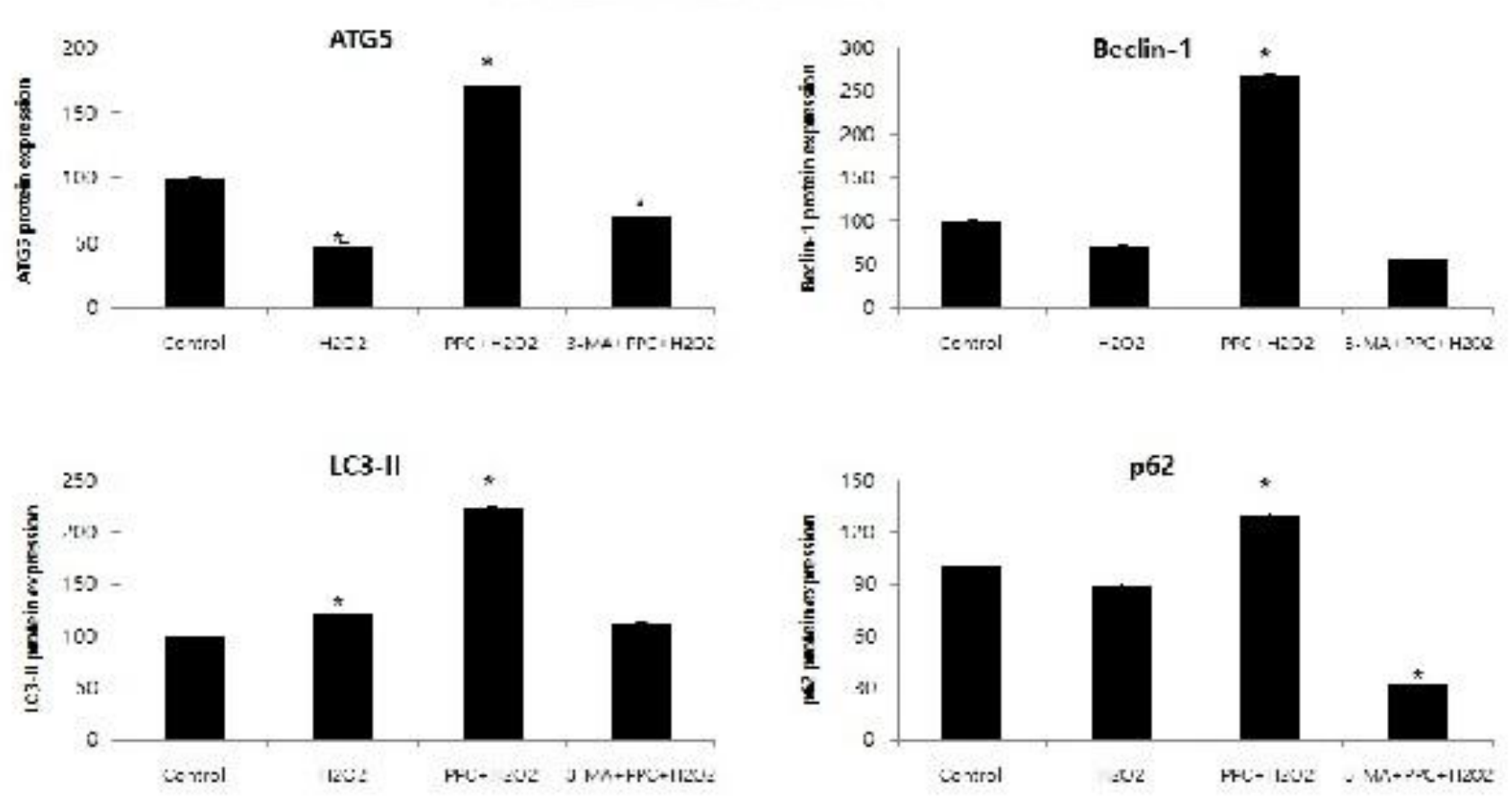

p62

\section{Conclusions}

This study suggests that propofol preconditioning has protective effect on $\mathrm{H}_{2} \mathrm{O}_{2}$-induced COS-7 cell death, which is mediated by autophagy activation. 